\title{
BMJ Open Lifetime smoking habits among Norwegian men and women born between 1890 and 1994: a cohort analysis using cross-sectional data
}

\author{
Ingeborg Lund, Karl Erik Lund
}

To cite: Lund I, Lund KE. Lifetime smoking habits among Norwegian men and women born between 1890 and 1994: a cohort analysis using cross-sectional data. BMJ Open 2014;4:e005539. doi:10.1136/bmjopen-2014005539

- Prepublication history for this paper is available online. To view these files please visit the journal online (http://dx.doi.org/10.1136/ bmjopen-2014-005539).

Received 24 April 2014 Revised 4 August 2014 Accepted 28 August 2014

CrossMark

Norwegian Institute for Alcohol and Drug Research (SIRUS), Oslo, Norway

Correspondence to Dr Ingeborg Lund; il@sirus.no

\section{ABSTRACT}

Objectives: Providing lifetime smoking prevalence data and gender-specific cigarette consumption data for use in epidemiological studies of tobacco-induced cancer in Norway. Characterising smoking patterns in birth cohorts is essential for evaluating the impact of tobacco control interventions and predicting smoking-related mortality.

\section{Setting: Norway.}

Participants: Previously analysed annual surveys of smoking habits from 1954 to 1992, and individual lifetime smoking histories collected in 1965 from a sample of people born in 1893-1927, were supplemented with new annual surveys of smoking habits from 1993 to 2013. Age range 15-74 years.

Primary outcome measure: Current smoking proportions in 5-year gender-and-birth cohorts of people born between 1890 and 1994.

Results: The proportion of smokers increased in male cohorts until the 1950s, when the highest proportion of male smokers $(76-78 \%)$ was observed among those born in 1915-1934. Among women, the peak (52\%) occurred 20 years later, in women born in 1940-1949. After 1970 smoking has declined in all cohorts of men and women. In the 1890-1894 cohorts, male smoking prevalence was several times higher than female, but the gap declined until no gender difference was present among those born after 1950. Gender-specific per capita consumption was even more skewed, and men have consumed over $70 \%$ of all cigarettes since 1930 . The incidence of lung cancer for men peaked at around 2000, with the highest incidence rate estimated at ca. 38\%. The incidence of lung cancer for women is still increasing, and estimated incidence rate for 2011 was $25.2 \%$.

Conclusions: In an epidemiological perspective, men have had a longer and more intense exposure to cigarettes than women. The gender-specific incidence of lung cancer reflects the gender difference in consumption over time.

\section{INTRODUCTION}

The rise and fall in smoking prevalence over time is remarkably similar across developed countries. From being almost non-existent in

\section{Strengths and limitations of this study}

- The study gives an update of smoking prevalence in Norwegian cohorts for the past 25 years, a period characterised by extensive tobacco control activity. The total time-span included in the study is close to 90 years.

- The historic association between the genderspecific lung cancer incidence and the gender difference in consumption is inspected.

- Mapping cigarette consumption over many generations is challenging in terms of accuracy of the measurements. In addition to the difficulties involved in measuring unregistered consumption, other factors that might have affected the results are increasing under-reporting of smoking status over time and the absence of a measure for excess mortality among smokers.

the late $1800 \mathrm{~s}$, cigarette consumption rose exponentially and peaked around the middle of the 20th century, in a development resembling the pattern produced by an epidemic with four distinct phases. ${ }^{12}$

In the first phase (1900-1920), increased popularity of cigarettes, particularly in higher social strata, signalled the initiation of mass smoking among men, while for women smoking remained marginal. In the second phase (1920-1950), smoking prevalence increased sharply. Generally more than half the men and around $20 \%$ of women were smokers at the end of this period. During the third phase (1950-1980), smoking among men started to decline, especially in groups with a higher socioeconomic status, while smoking among women reached a maximum of approximately $40 \%$. In the last phase, which is still continuing (1980-), smoking prevalence has gone down, and is currently at around $20 \%$ for both genders. ${ }^{34}$

Tobacco smoking caused an estimated 13\% of deaths in Norway for people over the age 
of 35 in 2009..$^{5}$ The close association between smoking duration and most smoking-related diseases implies that, in addition to smoking prevalence, the age-composition of the smoking population influences this mortality. The incidence of lung cancer provides an excellent example of the long delay that can exist between aggregated tobacco consumption and the occurrence of disease. ${ }^{6}$ Findings have indicated that lung cancer is more closely associated with smoking duration than with smoking intensity. $^{78}$

Improved knowledge about smoking prevalence in different age groups might facilitate better predictions of the future health consequences from smoking.

The historic diffusion of cigarette smoking in Norway until the beginning of the 1990s, reflecting the first three stages of the diffusion model, ${ }^{1}$ has been established by Rønneberg, Lund and Hafstad, ${ }^{9}$ and Lund. ${ }^{10}$ Since then, another quarter of a century can be added to the 100-year period of mass-consumption of cigarettes in Norway. During this last period, nearly all antismoking political measures recommended by the WHO have been implemented in Norway. Norway currently has one of the highest rankings in a European index of tobacco control activities. ${ }^{11}$

The slow dynamic of the epidemic, and the delay between aggregated tobacco consumption and disease, highlight the importance of a systematic study of cigarette consumption over the past decades. On this background we have made an update of the development in Norwegian cigarette smoking trends, by adding new cohorts from the fourth stage, covering the period 1990-2013. We have also utilised prevalence data from the analysis of cohorts from 1890 to 2013 to establish gender-specific consumption data in order to describe the association between cigarette use and lung cancer incidence in a long-term perspective in Norway.

\section{METHODS}

We have updated the previous results of Rønneberg et at ${ }^{\beta}$ with new data for the years 1992-2013, using the same methodology and measures as in the 1994-study.

\section{Data sources}

For the years until 1992, the estimated prevalence of smokers in birth cohorts was retrieved directly from the study by Rønneberg et al, ${ }^{9}$ in which data from three different sources was combined to obtain prevalence data for birth cohorts from 1890 to 1974 (table 1). First, for the years prior to 1955, the information came from a cross-sectional survey conducted in 1965, in which the Cancer Registry of Norway collected retrospective smoking histories from a representative sample of men and women born in 1893-1927. Second, information on smoking status split by gender and age groups for the period 1954-1973 was taken from biannual reports based on monthly telephone surveys, and published by the commercial pollster Nielsen Norway.
Third, for the years 1973-1992, data on smoking status was obtained from annual cross-sectional surveys among 15-74-year-olds, conducted by Statistics Norway, a government body responsible for official statistics.

This series of annual cross-sectional surveys was the source also for the additional data used in the current study, calculated for the years 1993-2013. For all these surveys (1973-2013), samples of 15-74-year-olds were drawn from Statistics Norway's own database, updated each month with the National Population Register, and representative of the population in the survey years. The gross sample sizes before 1993 included 2500-3000 people each year, with response rates ranging from $63 \%$ to $80 \%$, with a decreasing tendency over time. ${ }^{3}$ For the years 1993-2013, yearly gross sample sizes were 25007900 people, and response rates were in the range 55$71 \%$, decreasing over time. Group sizes (within gender and birth cohorts) ranged from 306 to 6673 individuals, with the earliest cohorts represented by the smallest number of people, and cohorts born in the mid-1950s with the largest.

\section{Measures}

The proportion of daily smokers in 5-year gender-and-birth cohorts, defined as all those of one gender born in the same 5-year period, was calculated for progressive ages from the sources listed in table 1. Years of birth ranged from 1890 to 1994 . Smokers included daily users of manufactured cigarettes, roll-your-own, pipe tobacco, cigars or a combination of these.

Total sales: The Norwegian Directorate of Customs and Excise have recorded domestic annual sales of tobacco since 1927. Sales of loose tobacco have been reported by weight, and manufactured cigarettes were converted to weight from the registered number sold (1 cigarette equals $1 \mathrm{~g}$ ). Estimates of the magnitude of border trade and travellers' tobacco import ${ }^{12-14}$ were added to registered sales.

Relative proportion of tobacco consumption: Prevalence estimates and consumption intensities were obtained from the sources listed in table 1 . To increase the stability of the results, all calculations were based on 3-year moving averages. Interpolation was used to replace missing consumption data.

For each year (1927-2013), smoking prevalences for men and women were multiplied by the number of male and female inhabitants over 15 years, obtained from Statistics Norway. The resulting gender-specific number of smokers was multiplied by average selfreported daily consumption giving a measure for accumulated daily consumption within each gender and for each year. These accumulated daily consumption measures were used to calculate the gender proportion of consumption for the years 1927-2013, accounting for gender differences in consumption intensity and smoking prevalence.

Gender-specific per capita consumption: Total annual sales (registered+unregistered) were multiplied with the 
Table 1 Data sources for smoking habits in the population

\begin{tabular}{|c|c|c|c|c|}
\hline Source & Data obtained by: & Sample size & Age range & Available as: \\
\hline $\begin{array}{l}\text { Nielsen Norway's monthly } \\
\text { surveys } 1954-1992^{*}\end{array}$ & Guided interview & $\begin{array}{l}12000- \\
20000 \text { per } \\
\text { year }\end{array}$ & $\begin{array}{l}\text { 1954-1957: 18-29, } \\
\text { 30-44, 45-59, 60+ } \\
\text { 1958-1966: 15-29, } \\
30-44,45-59,60+ \\
\text { 1967-1992: 15-19, } \\
20-29,30-44,45-64 \\
65+\end{array}$ & $\begin{array}{l}\text { Half-yearly reports with results } \\
\text { tabulated for each age group }\end{array}$ \\
\hline $\begin{array}{l}\text { The Cancer Registry } \\
\text { survey } 1965^{\star}\end{array}$ & $\begin{array}{l}\text { Self-administered } \\
\text { questionnaire }\end{array}$ & 14245 & $37-73$ & Individual data \\
\hline $\begin{array}{l}\text { Statistics Norway's } \\
\text { annual surveys } 1973-92^{*}\end{array}$ & Guided interview & $\begin{array}{l}2500-3000 \\
\text { per year }\end{array}$ & $15-74$ & Individual data \\
\hline $\begin{array}{l}\text { Statistics Norway's } \\
\text { annual surveys } \\
\text { 1993-2013 }\end{array}$ & Guided interview & $\begin{array}{l}\text { 2500-7900 } \\
\text { per year }\end{array}$ & $15-74$ & Individual data \\
\hline
\end{tabular}

relative proportion consumed by each gender. To obtain annual per capita figures, total consumption was divided by the number of inhabitants over 15 years.

Age-adjusted incidence rates for lung cancer (International Classification of Diseases 10 (ICD 10) code C33-34) per 100000 person-years for the period 1957-2011 were obtained from the Cancer Registry of Norway. $^{15}$

\section{RESULTS}

\section{Birth-cohort perspective}

Over the last century, there has been large variability in the proportion of smokers within and across cohorts (table 2). Within male cohorts the typical development has been a gradual increase in the proportion of smokers from the youngest age groups and up to the age of 30 , when the situation tended to stabilise for a number of years, followed by a decline in smoking prevalence in the higher age groups. While in the earliest cohorts this decline usually started around the age of 60, an increasing tendency in later cohorts has been for this decline to start earlier in life. For cohorts born after 1950, smoking prevalence started to decline as early as the age of 30 , and in effect there was no prolonged period of stable smoking prevalence in the subsequent cohorts.

The highest proportions of male ever-smokers were observed in cohorts born between 1905 and 1935, with peak prevalence often above $70 \%$, and occurring when the cohorts were between 20 and 45 years old. The single highest smoking prevalence of $78 \%$ was found for the age group 20-24 years, for the cohort born in 19251929.

Among women, the prevalence of smoking has changed in a similar manner, but with a 20-year time-lag, and at lower (peak) prevalence levels. The highest prevalence reached by women was $52 \%$ among 25-29-year-olds from the 1940 to 1944 cohort, and 20-24-year-olds from the 1945 to 1949 cohort. Even for female cohorts there was a clear tendency for the proportion of smokers to increase in younger age groups and decline towards old age. As for men, this decline tended to set in at earlier ages in later cohorts.

A more visual way to illustrate these findings is displayed in figure 1, where the age and birth dates are used to calculate smoking prevalence in cohorts in 5-year intervals from 1915 to 2010. Similar to table 2, figure 1 shows how the proportion of smokers first increased and then decreased with age within all cohorts. The differences in absolute levels and the time-lag between men and women are also clearly demonstrated.

The downward trend observed in male cohorts after the mid-1950s ${ }^{9}$ has continued to the end of our observation period. For female cohorts, the sign of a decline started to appear in some cohorts after the mid-1970s, while the years after 1990 have been characterised by declining smoking prevalence in all cohorts. Large groups of smokers within the younger female cohorts had quite short smoking careers. Women born during 1970-1974 for example, sustained the maximum cohort smoking prevalence of 32-33\% only for about $0.5-1$ decade before it started to diminish in the first half of the 2000s.

\section{Age-group perspective}

Variations in smoking over time are also demonstrated in figure 2, where the proportion of smokers in three specific age groups (15-19, 25-29 and 70-74 years) are drawn as coloured lines. The cohorts from figure 1 are indicated in grey. Among men, the youngest age group has consistently had a lower prevalence of smoking than the older age groups. Among women, 15-19-year-olds have tended to smoke more than higher age groups from earlier cohorts. For both genders, 25-29-year-olds 
Table 2 The proportion of current smokers for Norwegian men and women by 5-year birth cohorts 1890-1994, and 5-year age groups $15-74$ years ${ }^{*}$

\section{The proportion of smokers by age (\%)}

Birth cohorts

\section{5-19 20-24 25-29 30-34 $35-39$}

\section{Men}

\begin{tabular}{|c|c|c|c|c|c|c|c|c|c|c|c|c|}
\hline 1890-1894 & 37 & 53 & 56 & 57 & 56 & 57 & 57 & 57 & 57 & 57 & 46 & 39 \\
\hline 1895-1899 & 40 & 57 & 61 & 61 & 61 & 62 & 62 & 63 & 62 & 52 & 45 & 41 \\
\hline 1900-1904 & 43 & 62 & 66 & 68 & 68 & 69 & 69 & 68 & 59 & 53 & 47 & 32 \\
\hline 1905-1909 & 44 & 63 & 67 & 70 & 71 & 71 & 70 & 66 & 56 & 53 & 43 & 39 \\
\hline 1910-1914 & 47 & 67 & 71 & 74 & 74 & 73 & 68 & 61 & 58 & 52 & 41 & 32 \\
\hline $1915-1919$ & 46 & 70 & 75 & 77 & 75 & 73 & 65 & 61 & 50 & 40 & 42 & 33 \\
\hline 1920-1924 & 49 & 75 & 76 & 75 & 73 & 67 & 61 & 57 & 44 & 42 & 33 & 29 \\
\hline 1925-1929 & 55 & 78 & 76 & 73 & 67 & 61 & 61 & 48 & 48 & 38 & 30 & 25 \\
\hline 1930-1934 & 57 & 76 & 71 & 66 & 61 & 52 & 41 & 43 & 42 & 29 & 28 & 19 \\
\hline 1935-1939 & 57 & 70 & 61 & 61 & 54 & 42 & 46 & 39 & 37 & 28 & 20 & 17 \\
\hline 1940-1944 & 42 & 57 & 60 & 52 & 48 & 46 & 41 & 37 & 29 & 27 & 17 & \\
\hline 1945-1949 & 35 & 52 & 54 & 48 & 47 & 42 & 38 & 35 & 28 & 23 & & \\
\hline 1950-1954 & 36 & 51 & 49 & 46 & 43 & 40 & 39 & 28 & 24 & & & \\
\hline 1955-1959 & 37 & 40 & 41 & 45 & 40 & 35 & 31 & 26 & & & & \\
\hline 1960-1964 & 27 & 38 & 36 & 37 & 33 & 27 & 23 & & & & & \\
\hline 1965-1969 & 25 & 37 & 38 & 34 & 28 & 20 & & & & & & \\
\hline 1970-1974 & 18 & 32 & 33 & 24 & 20 & & & & & & & \\
\hline 1975-1979 & 26 & 33 & 26 & 19 & & & & & & & & \\
\hline 1980-1984 & 23 & 27 & 21 & & & & & & & & & \\
\hline $\begin{array}{l}1985-1989 \\
1990-\end{array}$ & $\begin{array}{r}17 \\
8\end{array}$ & 18 & & & & & & & & & & \\
\hline \multicolumn{13}{|l|}{ Women } \\
\hline 1890-1894 & 1 & 2 & 3 & 3 & 4 & 6 & 7 & 9 & 10 & 10 & 4 & 5 \\
\hline 1895-1899 & 1 & 3 & 4 & 5 & 7 & 10 & 12 & 15 & 15 & 10 & 8 & 7 \\
\hline 1900-1904 & 1 & 4 & 7 & 10 & 13 & 16 & 19 & 21 & 15 & 13 & 13 & 7 \\
\hline 1905-1909 & 2 & 8 & 11 & 15 & 20 & 24 & 26 & 21 & 18 & 19 & 11 & 11 \\
\hline 1910-1914 & 4 & 11 & 17 & 23 & 27 & 30 & 25 & 22 & 24 & 19 & 12 & 10 \\
\hline 1915-1919 & 5 & 15 & 24 & 31 & 35 & 30 & 27 & 29 & 24 & 22 & 13 & 16 \\
\hline 1920-1924 & 8 & 26 & 36 & 37 & 34 & 34 & 34 & 32 & 25 & 24 & 21 & 16 \\
\hline 1925-1929 & 13 & 37 & 40 & 37 & 38 & 38 & 35 & 30 & 29 & 27 & 22 & 15 \\
\hline 1930-1934 & 23 & 42 & 40 & 38 & 43 & 37 & 37 & 35 & 33 & 27 & 22 & 15 \\
\hline 1935-1939 & 28 & 40 & 39 & 47 & 42 & 32 & 38 & 31 & 31 & 23 & 18 & 15 \\
\hline 1940-1944 & 27 & 39 & 52 & 39 & 36 & 34 & 38 & 34 & 30 & 23 & 17 & \\
\hline 1945-1949 & 26 & 52 & 46 & 42 & 40 & 39 & 36 & 36 & 28 & 21 & & \\
\hline 1950-1954 & 35 & 47 & 43 & 44 & 44 & 37 & 39 & 30 & 23 & & & \\
\hline 1955-1959 & 36 & 42 & 45 & 43 & 41 & 33 & 30 & 27 & & & & \\
\hline 1960-1964 & 29 & 41 & 41 & 37 & 34 & 32 & 24 & & & & & \\
\hline 1965-1969 & 23 & 34 & 34 & 34 & 28 & 24 & & & & & & \\
\hline 1970-1974 & 24 & 32 & 31 & 25 & 18 & & & & & & & \\
\hline 1975-1979 & 23 & 31 & 23 & 16 & & & & & & & & \\
\hline 1980-1984 & 27 & 29 & 20 & & & & & & & & & \\
\hline 1985-1989 & 17 & 19 & & & & & & & & & & \\
\hline $1990-$ & 10 & & & & & & & & & & & \\
\hline
\end{tabular}

${ }^{*}$ Numbers in italics are from Rønneberg et al. ${ }^{9}$

have had a high proportion of smokers relative to other age groups. Among women this was the age at which smoking prevalence was highest until approximately 1985. The smoking prevalence in the oldest age group has consistently been quite low for both genders. However, while the proportion of smokers among 7074-year-olds has been declining among men since the end of the 1970s, it has remained stable among women since the mid-90s.

\section{Gender-specific cigarette consumption}

For men, annual consumption of cigarettes per person (over 15 years) peaked at $2.8 \mathrm{~kg}$ in the middle of the 1970s (figure 3). Approximately 30 years later, consumption had reduced to $1.5 \mathrm{~kg}$, about the same as at the end of the 1920s. For women, consumption peaked at around 1990, at $1.8 \mathrm{~kg}$ per person. After this, consumption decreased to about $1.2 \mathrm{~kg}$ in 2010 . The result of the combined effect of higher prevalence rates and higher 


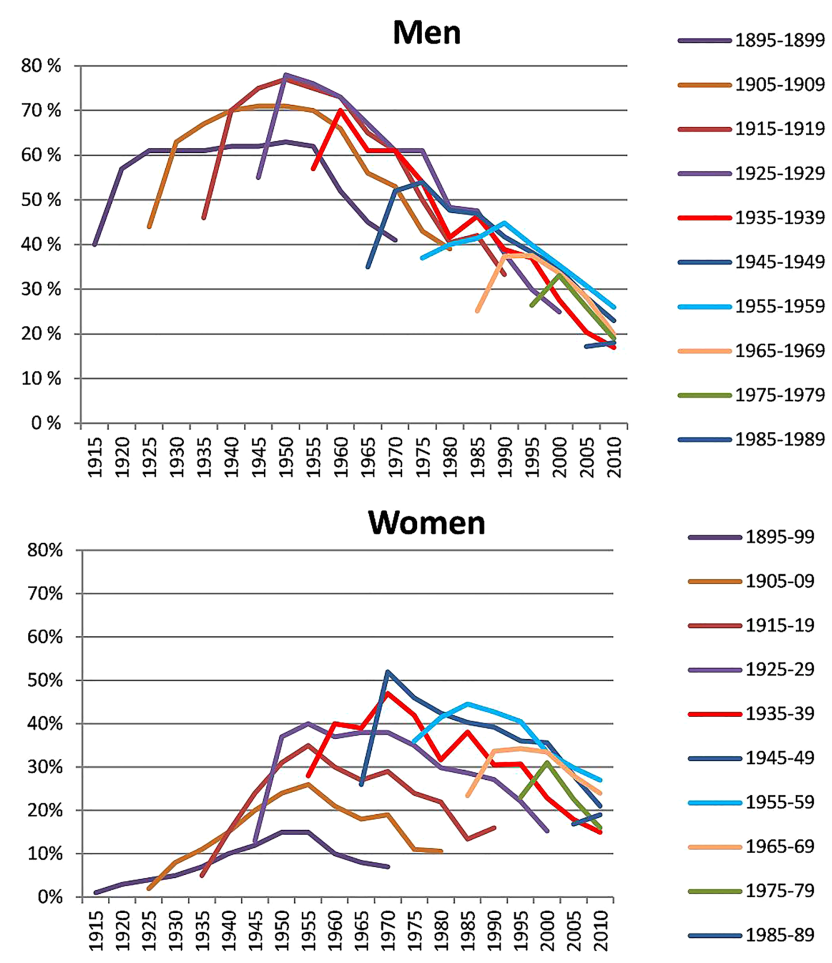

Figure 1 The proportion of current smokers 1915-2010 in Norwegian men and women by birth cohort.

consumption intensities was that men consumed about $95 \%$ of all cigarettes around 1930, while in the past few decades they consumed about $55 \%$ of the total quantity.

Figure 3 also depicts time trends for the incidence of lung cancer. Among men, the rate increased rapidly throughout the second half of the 20th century, and peaked around 2000, with a maximum incidence rate of approximately $38 \%$. Among women, the rate has been considerably lower, the increase started later, and the incidence has not yet peaked. In 2011 the female incidence rate was $25.2 \%$. The latency period between cigarette exposure and lung cancer incidence was around 30 years for both genders, confirming results from earlier research. ${ }^{15} 16$

\section{DISCUSSION}

Our study shows that the 20th century smoking epidemic hit Norwegian men much harder than women. While consumption of cigarettes per capita for men reached a maximum of $3 \mathrm{~kg}$ around 1970, consumption for women reached an all-time high of $1.7 \mathrm{~kg}$ in the $1990 \mathrm{~s}$. The gender-specific lung cancer trends, with a levelling off observed in men in recent years and a rapid increase in women, largely reflect the time lags in tobacco use patterns for men and women.

The all-time maximum smoking prevalence of around $75 \%$ was found during the $1950 \mathrm{~s}$, among men born between 1920 and 1935, who were then in their 30s and 40s. For male cohorts born after 1935, our study demonstrates a steady drop in peak smoking prevalence, a
Men
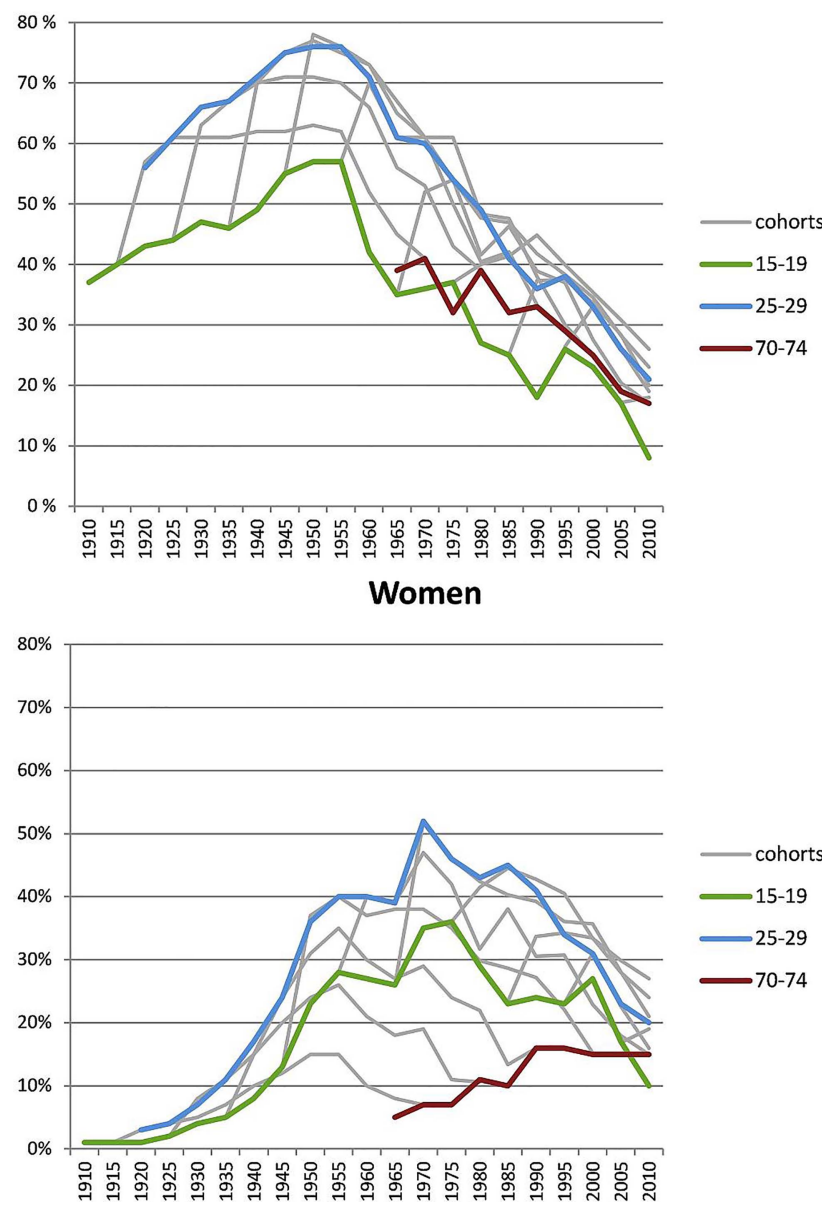

Figure 2 The proportion of current smokers in three Norwegian age groups 1905-2013.

trend that has continued in the most recent cohorts. For women, peak smoking prevalence increased until the 1940-1944 cohort reached their late 20s around 1970. Peak prevalence has then dropped in successive cohorts.

All cohorts of men reported higher daily cigarette consumption than women during the entire period. This difference explains why men continued to consume more tobacco than women, despite the

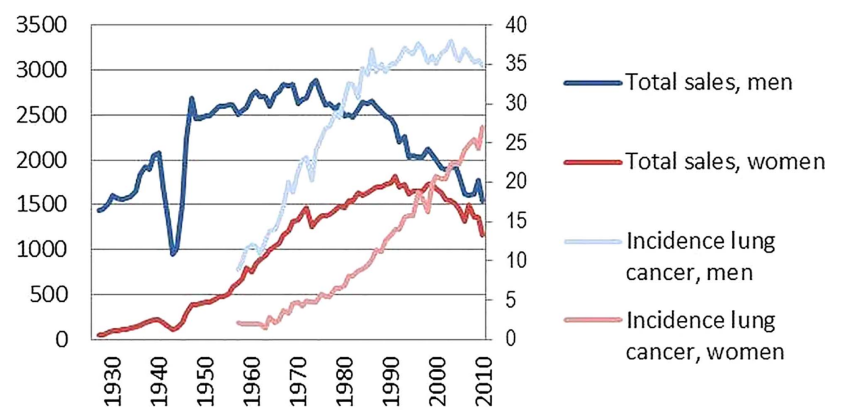

Figure 3 Estimated total annual sales in grams per capita 1927-2013 (registered and unregistered) and yearly lung cancer incidence 1957-2010, men and women. 
gender-convergence in smoking prevalence in cohorts born after 1970. Owing to their longer and more intense exposure to cigarettes, men have consumed more than $70 \%$ of the approximately 1.5 trillion cigarettes smoked in Norway since 1930.

\section{Age, cohort and period effects}

Age, period and cohort effects are mathematically dependent, and cannot be studied independently. Smoking tends to be reduced by age, particularly after mid-life. External shocks may influence smoking prevalence across all ages, and create period effects. New cohorts might take up smoking to a larger or smaller degree than previous cohorts. Our results reflect all these effects. Reduced smoking prevalence in older age is a typical trait of all cohorts, although the point at which this reduction starts has shifted downwards. Period effects and cohort effects can be particularly difficult to separate. Since the 1960s, the smoking environment has been characterised by a series of external shocks as regulations and limitations have become progressively stricter, and the level of knowledge about harms from smoking has increased. While increased tobacco consumption in the first half of the 1900s coincided with extensive commercial pressure linking cigarette smoking with modernism, a refined lifestyle, and elegance ${ }^{10}$ the decline in tobacco consumption among men started at the time when nationwide tobacco legislation was implemented. In 1975, the first publicly financed health information campaign was launched by the State Information Services. In the same year, a total ban on all tobacco commercials was implemented, health warnings on cigarette and tobacco packs were introduced, and a 16-year age limit for buying and selling tobacco became effective. The law was later expanded to protect people from passive smoking in work places and means of transportation (1989), and in places where food was served (2004), new nicotine products were banned (1989), more (1984) and larger (2003) health warnings were introduced and the age limit for buying and selling tobacco was raised to 18 years (1995). The real price of tobacco increased several times, systematic preventive measures were instigated, and campaign activity was intensified.

These initiatives from the authorities have probably stimulated both period effects, discouraging existing smokers of all ages from continued smoking, and cohort effects, such that fewer people from new cohorts would take up smoking, for example due to reduced availability for adolescents after the introduction of age limits. Interaction between period and cohort effects is also not unlikely.

One might for example argue that reduced smoking among parents, which could be a result of a period effect, stimulates a child-rearing atmosphere which discourages smoking, thus accelerating a cohort effect for the next generation.
Factors outside the direct control of the authorities, such as the changed symbolic content of smoking, the lowered status of user groups, have most likely aided these processes. In addition it is probable that the launching of nicotine-containing drugs to quit smoking, and the renaissance of the smokeless tobacco snus, have influenced both smoking cessation rates and smoking initiation rates in this time period.

\section{Duration of smoking careers}

Our results suggest that the time frame for maximum smoking prevalence within cohorts has been shrinking, from including the larger part of adult life for those born in the first half of the 20th century, to involving only people in their 20 s and 30 s for those born in the second half. This result is not unique to the current study. A study of US cohorts born between 1900 and 1980, showed that cessation rates started to increase from age 30 after 1960 for men, and after 1970 for women, ${ }^{17}$ while increasing age-specific cessation rates were seen in progressively more recent US cohorts born after $1965 .{ }^{18}$ For Ontario-cohorts born between 1940 and 1975 , Birkett ${ }^{19}$ found that the period until one-third of the smokers had quit was much reduced from the 1940 cohort to the 1970 cohort. An analysis of British birth cohorts from the 20th century similarly showed that the age at which smokers quit appeared to be falling in successive cohorts. ${ }^{20}$

Seen in the light of the long-term character of most smoking-related diseases, the tendency for shorter smoking careers is positive. An important factor in the long-term effect on public health is not just how many adolescents start smoking, but also how the proportion that smokes varies within birth cohorts as people reach middle to old age. As shown repeatedly, ${ }^{21-23}$ even middle-aged smokers who quit smoking will increase their life expectancy to almost never-smoking levels within a few years. However, long time lags between population smoking and disease implies that health improvements at the population level may take some time to materialise, as illustrated by the approximately 30-year time-lag between the incidence of lung cancer and sales of tobacco in figure 3 .

\section{Delays in changes among women}

Women started to smoke later than men both historically and biographically, a result also observed in Canada $^{19}$ and the USA. ${ }^{24}$ This gender difference must be interpreted in the light of the restrictive norms for female smokers, which prevented the industry from tailoring market campaigns specifically for women in the early days. The increase in smoking among women was associated with more liberal norms and the subsequent increase in marketing directed towards women. ${ }^{10}$

The authorities' antismoking campaigns started at an earlier point in the development of smoking habits for women than for men, and this has probably contributed 
to the lower level of tobacco consumption at the time of culmination among women.

The delayed decline in women's total tobacco consumption was caused by a cohort effect. In the 1970s, elderly female smokers were rare, as it had been uncommon for women to smoke when they were young in the 1920s and 30s. As the women who grew up in the more smoking-positive atmosphere in the 1950s grew older, their relatively high share of smokers diminished the effect of reduced consumption among women from more recent cohorts. However, this cohort effect decreased towards the turn of the century, and since then women have reduced their tobacco consumption to the same extent as men.

\section{Limitations}

Mapping cigarette consumption over a period of nearly 90 years is challenging in terms of accuracy of the measurements. Heterogeneity between the various surveys in terms of sampling methodology, administration of the questionnaire, and sample characteristics may have influenced the measures of smoking prevalence derived from each survey. Unregistered consumption is inherently difficult to measure correctly, some point estimates are missing (1940-1945) and the estimates include only border trade and tourist import, and not smuggling. Furthermore, the one-to-one conversion of cigarettes to weight is a simplification that has given estimates that are too high for recent years, as the weight of machinemade cigarettes has become somewhat reduced since the 1980s. However, results from representative surveys of supply sources have corresponded well with the industry-supplied information used to obtain the unregistered consumption estimates, and smuggling has been shown to have contributed only modestly to cigarette consumption in our study period. ${ }^{25}$

Interpolation and reconstruction was necessary for some annual prevalence and intensity observations early in the period, and some point observations are therefore less reliable for the years 1927-1954 than in later periods. Under-reporting of smoking status may have increased over time, as smoking now deviates more from accepted norms. ${ }^{26}$ The absence of a measure for excess mortality among smokers is also a limitation, as the lower proportion of smokers in older age groups results partly from excess smoker mortality.

Despite these limitations, we believe that the overview is representative for the development of cigarette consumption for both men and women.

\section{CONCLUSION}

Men have consumed more than $70 \%$ of all cigarettes smoked in Norway since 1930. In an epidemiological perspective, men have had a longer and more intense exposure to cigarettes than women. The reduction in smoking started in the 1950s in male cohorts, and in the $1970 \mathrm{~s}$ in female cohorts. The gender-specific lung cancer trends largely reflect the time-lag in tobacco use patterns for men and women, and confirm the 30-year latency period found previously.

Acknowledgements Establishing this historic overview of gender-specific tobacco consumption has been possible due to work on smoking habits by researcher Alf Rønneberg at the Norwegian Cancer Registry in 1994. Alf Rønneberg died in 1997.

Contributors IL performed most of the statistical analyses and drafted the manuscript. KEL helped to draft the manuscript and did some of the statistical analyses. Both authors read and approved the final manuscript.

Funding This research received no specific grant from any funding agency in the public, commercial or not-for-profit sectors.

Competing interests None.

Provenance and peer review Not commissioned; externally peer reviewed.

Data sharing statement No additional data are available.

Open Access This is an Open Access article distributed in accordance with the Creative Commons Attribution Non Commercial (CC BY-NC 4.0) license, which permits others to distribute, remix, adapt, build upon this work noncommercially, and license their derivative works on different terms, provided the original work is properly cited and the use is non-commercial. See: http:// creativecommons.org/licenses/by-nc/4.0/

\section{REFERENCES}

1. Lopez AD, Collishaw NE, Piha T. A descriptive model of the cigarette epidemic in developed countries. Tob Control 1994;3:242.

2. Thun M, Peto R, Boreham J, et al. Stages of the cigarette epidemic on entering its second century. Tob Control 2012;21:96-101.

3. Cavelaars AE, Kunst AE, Geurts JJ, et al. Educational differences in smoking: international comparison. BMJ 2000;320:1102.

4. Ferrence RG. Deadly fashion: the rise and fall of cigarette smoking in North America. New York: Garland, 1989.

5. Vollset SE, Selmer R, Magnus P. Hvor dødelig er røyking? Beregninger for 2009. Oppdatering av tabell A2, FHI-rapport 2006:4 [How deadly is smoking? Calculations for 2009. An update of table A2, FHI report 2006:4]. Oslo: Norwegian Institute of Public Health, 2011. http://www.fhi.no/dokumenter/45d7c26ad4.pdf

6. Davis VN, Lavender A, Bayakly R, et al. Using current smoking prevalence to project lung cancer morbidity and mortality in Georgia by 2020. Prev Chronic Dis 2013;10:E74.

7. Flanders WD, Lally CA, Zhu B-P, et al. Lung cancer mortality in relation to age, duration of smoking, and daily cigarette consumption: results from cancer prevention study II. Cancer Res 2003;63:6556-62.

8. Peto R. Influence of dose and duration of smoking on lung cancer rates. IARC Sci Publ 1986;74:23-33.

9. Rønneberg A, Lund KE, Hafstad A. Lifetime smoking habits among Norwegian men and women born between 1890 and 1974. Int $J$ Epidemiol 1994;23:267-76.

10. Lund KE. Samfunnsskapte endringer i tobakksbruk i Norge i det 20. århundre [Social influences on tobacco behavior in the 20th century Norway]. Oslo: Institute for sociology and human geography, University of Oslo, 1996. 383s. p.

11. Joossens L, Raw M. The Tobacco Control Scale: a new scale to measure country activity. Tob Control 2006;15:247-53.

12. Lund KE. Tobakksavgiften som helsepolitisk styringsinstrument [The tobacco tax as a regulatory tool in health politics]. Oslo: SIRUS, 2005 Skrifter No 4.

13. Lund K, Lund M, Bryhni A. [Tobacco consumption among men and women 1927-2007]. Tidsskr Nor Laegeforen 2009;129:1871-4.

14. Horverak $\varnothing$. Avgiftsfritt salg av alkohol og tobakk på norske flyplasser i 2012 [Tax Free sales of alcohol and tobacco from Norwegian airports in 2012]. Oslo, Norway: SIRUS, 2013.

15. Cancer Registry of Norway. Cancer in Norway 2011-Cancer incidence, mortality, survival and prevalence in Norway. Oslo: Cancer Registry of Norway, 2013. http://www.kreftregisteret.no/ Global/Cancer\%20in\%20Norway/2011/cin2011_with_special_ issue-NORDCAN.pdf

16. Weiss W. Cigarette smoking and lung cancer trends. A light at the end of the tunnel? Chest 1997;111:1414- 16. 
17. Harris JE. Cigarette smoking among successive birth cohorts of men and women in the United States during 1900-80. J Natl Cancer Inst 1983;71:473-9.

18. Anderson CM, Burns DM, Dodd KW, et al. Birth-cohort-specific estimates of smoking behaviors for the US population. Risk Anal 2012;32(Suppl 1):S14-24.

19. Birkett NJ. Trends in smoking by birth cohort for birth between 1940 and 1975: a reconstructed cohort analysis of the 1990 Ontario health survey. Prev Med 1999;26:534-41.

20. Kemm JR. A birth cohort analysis of smoking by adults in Great Britain 1974-1998. J Public Health Med 2001;23:306-11.

21. Doll R, Peto R, Wheatley $\mathrm{K}$, et al. Mortality in relation to smoking: 40 years' observations on male British doctors. BMJ 1994; 309:901-11.
22. Jha $\mathrm{P}$, Ramasundarahettige $\mathrm{C}$, Landsman $\mathrm{V}$, et al. 21st-century hazards of smoking and benefits of cessation in the United States. N Engl Med 2013;368:341-50.

23. Pirie K, Peto R, Reeves GK et al. The 21st century hazards of smoking and benefits of stopping: a prospective study of one million women in the UK. Lancet 2013;381:133-41.

24. Holford TR, Levy DT, McKay LA, et al. Patterns of birth cohort-specific smoking histories, 1965-2009. Am J Prev Med 2014;46:e31-7.

25. Lund KE. Omfanget av grensehandel, taxfreeimport og smugling av tobakk til Norge [The scale of border trade, tax-free import and tobacco smuggling to Norway]. Tidsskr Nor Laegeforen 2004;124:35-8.

26. Gallus S, Tramacere I, Boffetta P, et al. Temporal changes of under-reporting of cigarette consumption in population-based studies. Tob Control 2011;20:34-9. 